\title{
USING VALUE-FOCUSED THINKING IN BRAZIL
}

\author{
Danielle C. Morais ${ }^{1 *}$, Luciana H. Alencar ${ }^{1}$, \\ Ana Paula C.S. Costa ${ }^{1}$ and Ralph L. Keeney ${ }^{2}$
}

Received April 13, 2012 / Accepted August 16, 2012

\begin{abstract}
Value-Focused Thinking (VFT) provides a systematic approach to structure complex decisions for subsequent analysis. It is a powerful complement to decision analysis and its application has been growing in recent years. This paper discusses the application of VFT in Brazil to three problems in different contexts: water management, information system/information technology (IS/IT) strategic planning, and the disposal of plaster waste. This article describes how the VFT approach was used to structure these decision problems and identify alternatives to stall them, which led to developing qualitative and quantitative models for evaluating the alternatives, and discusses how such structures can be used in other similar problems.
\end{abstract}

Keywords: VFT, water management, IS/IT strategic planning, disposal of plaster.

\section{INTRODUCTION}

In the last twenty years, Value-Focused Thinking (VFT) (Keeney, 1992) has been applied in a wide range of contexts in order to identify the objectives of decision makers (DMs), including those who work in the military sector, or on such areas as mobile technology, tourist management, terrorists' objectives, environmental aspects, and telecommunications management.

In the military context, VFT was applied to selecting an automatic rifle for the Croatian Armed Forces (Peharda \& Hunjak, 2008) and to identify innovative ideas to improve the ability of the Air Force to execute its core competence (Jurk et al., 2004). Noteworthy is a VFT application for identifying and structuring the objectives of terrorists (Keeney \& Winterfeldt, 2010). The main question in that paper is "What do terrorists want" and VFT was applied to identify the terrorist's strategic objectives and the fundamental objectives and their means to accomplish the strategic objectives. Then there is discussion on how to use such knowledge to support analysts to make recommendations about counterterrorism.

\footnotetext{
*Corresponding author

${ }^{1}$ Federal University of Pernambuco, Production Engineering Department. E-mails: daniellemorais@yahoo.com.br; alencarlh@gmail.com; apcabral@hotmail.com

${ }^{2}$ The Fuqua School of Business, Duke University, Durham, NC 27708-0120, USA. E-mail: keeney@duke.edu
} 
In the context of technology, VFT was applied to understand the values of education available by mobile technology and to use such values as guidelines for implementing the use of mobile technology in education (Sheng et al., 2010) and VFT has also been used to examine the strategic implications of mobile technology in a leading publishing company (Sheng et al., 2005). Still within the context of technology, more specifically in telecommunication problems, VFT was applied to build a value model for telecommunications management decisions (Keeney, 2001).

Regarding environmental questions, VFT was applied to develop a set of objectives for climate change policy decisions of the American government (Keeney \& McDaniels, 2001). Hassan (2003) addressed a common issue in environmental management, namely the comparative implications of building materials such as wood, masonry, and concrete. VFT was also applied to improve the quality of watersheds in Richmond, Virginia (Merrick \& Garcia, 2004) and to understand safety decisions made by domestic oil tanker operators (Merrick et al., 2005).

Another interesting decision context where VFT was applied is tourism management (Kajanus et al., 2004) to show the fundamental and means objectives for the vitality of rural areas.

These applications have shown that it is appropriate to use VFT in many different decision contexts. This approach not only helps to identify all of the relevant objectives, including previously unrecognized objectives, but it also provides logical and consistent way of identifying the relationships among objectives.

In this paper we will present three case studies that applied VFT in the northeast of Brazil: water management, Information System/Information Technology (IS/IT) strategic planning, and the disposal of plaster waste. The main focus is to present how these three different decision problems were structured and how feasible alternatives consistent with the DM's values were generated to solve the decision problems.

The paper is structured into the following sections. Section 2 briefly explains the VFT approach and presents a short description of the procedures used to identify and structure objectives, specifically focusing on those that are used in the sections on applications. Sections 3 to 5 present applications in Brazil: water management, IS/IT strategic planning, and the disposal of plaster waste. In Section 6, there is a discussion about how objectives can be used to identify alternatives for decision problems. Section 7 presents some final remarks.

\section{STRUCTURING OBJECTIVES}

Decision making methods usually introduce objectives for evaluating alternatives after alternatives have been established or given (Keeney, 1992). Instead, focus should be given to how such alternatives are or can be established, and the best way to achieve that is to think about values and objectives.

The reason that a decision maker wishes to make a decision is to achieve something of value. Hence, understanding what it is that one hopes to achieve can lead to both creating better alternatives and to better decisions. VFT focuses is on the decision maker's values, which are defined 
as anything a decision maker cares about in a decision process. An objective is an organized representation of a value in terms of a verb and an object, such as 'minimize cost' or 'reduce the amount of waste material'. Hence, values are made explicit by specifying the decision maker's objectives. The design of VFT emphasizes that in a decision problem, identifying the DM's objectives is more relevant than comparing well-known alternatives to solving the problem. The identification of values can lead to creating alternatives beyond those that already exist. In structuring the decision problem, first the context of the decision should be determined. Thereafter, the fundamental and means objectives, and the relationships among them, should be identified.

When a decision maker structures his/her objectives, he/she is also able not only to compare ready-made alternatives, but also to create alternatives that were not apparent at the beginning of the process, but now appear as desirable and feasible within the structure of the objectives and values. In decision situations involving different stakeholders, the creation of alternatives using a systematic approach is of major interest. In these situations, alternatives should be based on the stakeholders' values, since their values are the reason for their interest in the decision problem (Hassan, 2004).

Structuring objectives involves establishing a hierarchy of values starting from fundamental objectives (Keeney, 1992). The properties of a good set of fundamental objectives (Keeney, 2007) are to be complete (include all fundamental aspects of the consequences of the decision alternatives); nonredundant (avoid double counting of possible consequences); concise (reduce the number of objectives needed for the analysis of a decision); specific (objectives should be clearly specified so the degrees to which each objective may be achieved can be defined); and understandable (facilitate generation and communication of insights for guiding the decision making process).

Decision analysts usually elicit values in interviews with DMs and stakeholders. The interview process leads to specifying in detail the reasons for being interested in a given problem. Normally in the elicitation process to identify the values for a decision problem, values, criteria, objectives, goals, constraints and/or attributes are mixed together. Each item is then converted into an objective (i.e. a verb and an object) prior to structuring the objectives. Structuring the objectives is helpful in understanding the decision context better and necessary for any subsequent use of quantitative methods (i.e. to build value and/or utility function to evaluate the alternatives).

It is important to distinguish between "fundamental objectives" and "means objectives". Fundamental objectives concern the ends that DMs value in a specific decision context; means objectives are the methods to achieve these ends. It is important to bear in mind that ends and means are context dependent. Means objectives can suggest alternatives that will achieve the fundamental objectives. The VFT approach begins by identifying the objectives, separating them into fundamental and means objectives, and constructing a hierarchy of the fundamental objectives and a network of means-ends objectives that illustrates the relationships of all of the objectives.

The achievement of a fundamental objective is described by a consequence measured in terms of an attribute. Attributes can be classified as natural, constructed, and proxy. Natural attributes 
have a common interpretation and may appear to be obvious. For example, Brazilian reais is a natural attribute for the objective "minimize cost". If a natural attribute does not exist, it is possible to construct an attribute for an objective directly associated with it or to measure it indirectly using a proxy attribute.

The resulting structure of objectives (and attributes) allows the decision maker to have insights into the problem situation so he/she can concentrate his/her attention on high-value alternatives.

\section{WATER MANAGEMENT}

Tackling a water management problem is a very complex activity. It involves the allocation of water to its multiple uses, which affect human lives. When discussing a specific aspect of water management, such as a Water Supply Systems (WSS), it is important to have in mind that it is related to the service provided to a large number of citizens. With that perspective, it is recognized that a WSS operates efficiently in both its technical and administrative aspects by providing not only treated water, but also doing so without interruption and at a low tariff.

VFT was used to support the DMs of an operational area of a specific Brazilian Water Utility to understand its problems by considering its values and objectives in order to increase customers' satisfaction. The DMs were the process control manager and the energy efficiency manager. Both are engineers. The former is responsible for updating operational procedures and managing the implementation of a modern supervisory control system and the latter has the challenge of drawing up an energy efficiency policy.

Some interviews and discussions with the DMs were conducted about their values with respect to the purpose of providing good and efficient service to the population. Based on the information collected, we identified the DMs' strategic objective as to maximize operational efficiency. Table 1 presents the strategic objectives and hierarchy of the fundamental objectives.

The hierarchy of fundamental objectives highlighted four major areas: operational (infrastructure, quality and rationing), management, human resources, and water tariffs. The DMs believe that improvement in these four areas would, as a consequence, bring greater satisfaction to customers.

The network of means-ends objectives depicts how fundamental objectives can be achieved through means objectives, that is, how company's strategy to improve customer satisfaction can be achieved. The relationships between means objectives and fundamental objectives demonstrate how the various departments of the Water Utility impact customer satisfaction. Figure 1 shows the network of means-ends objectives.

A specific attribute was defined for each of the lower-level fundamental objectives in Table 1. Thus, there were a total of ten attributes, eight of which were natural and two constructed. The constructed attributes were improved water quality (by chemical indicators) and the reduction in the annual percentage increase of water tariffs (by examining the variation in the annual rate). The attributes indicate the degree to which the objectives are achieved. 
Table 1 - Strategic objective and hierarchy of fundamental objectives for the Water Utility.

\begin{tabular}{|l|}
\hline $\begin{array}{c}\text { Maximize operational efficiency to improve customers' } \\
\text { satisfaction with the Water Utility (strategic objective) }\end{array}$ \\
\hline 1. Improve operational management \\
1.1. Improve infrastructure \\
1.1.1. Expand the current water operational plant \\
1.1.2. Modernize current water operational plant \\
1.2. Improve water quality \\
1.3. Reduce water rationing \\
\hline 2. Improve the maintenance system \\
\hline 3. Improve staff qualifications \\
3.1. Improve operational staff qualifications \\
3.2. Improve maintenance staff qualifications \\
3.3. Improve administrative staff qualifications \\
3.4. Improve customer service staff qualification \\
\hline 4. Reduce the annual percentage increase of water tariffs \\
\hline
\end{tabular}

Once the objectives and attributes were defined, the strategic value function had ten attributes. This overall evaluation function has four major components concerning, respectively, (1) operational management, (2) the maintenance system, (3) the qualifications of staff, and (4) water tariffs. The additive value function was selected to combine the evaluation measures using single-dimensional value functions.

Value tradeoffs were used to calculate the scaling constants in the overall value function. The scaling constants for the objectives were assessed using swing weighting procedures. The weights were specified by considering the difference in the relative desirability of the implications between the worst to the best levels of each attribute.

It is worth mentioning that the decision makers already knew several alternatives that could be implemented to minimize the problems identified in the city's water supply system. However, it was impossible to immediately implement all the alternatives to improve the system. Thus, the VFT approach helped the DMs identify the relationships among the specific objectives to increase customers' satisfaction.

As the alternatives involve efforts from several areas of the company, the DMs decided to propose the creation of a group, a multi-department task-force, responsible for organizing the form, sequence, and timeframe of how these alternatives should be implemented. The following lists some alternatives generated for each area:

- Quality Control: Set up a new modern laboratory; Modify equipment; Install new analytical meters in strategic places in the distribution system; Train technicians. 


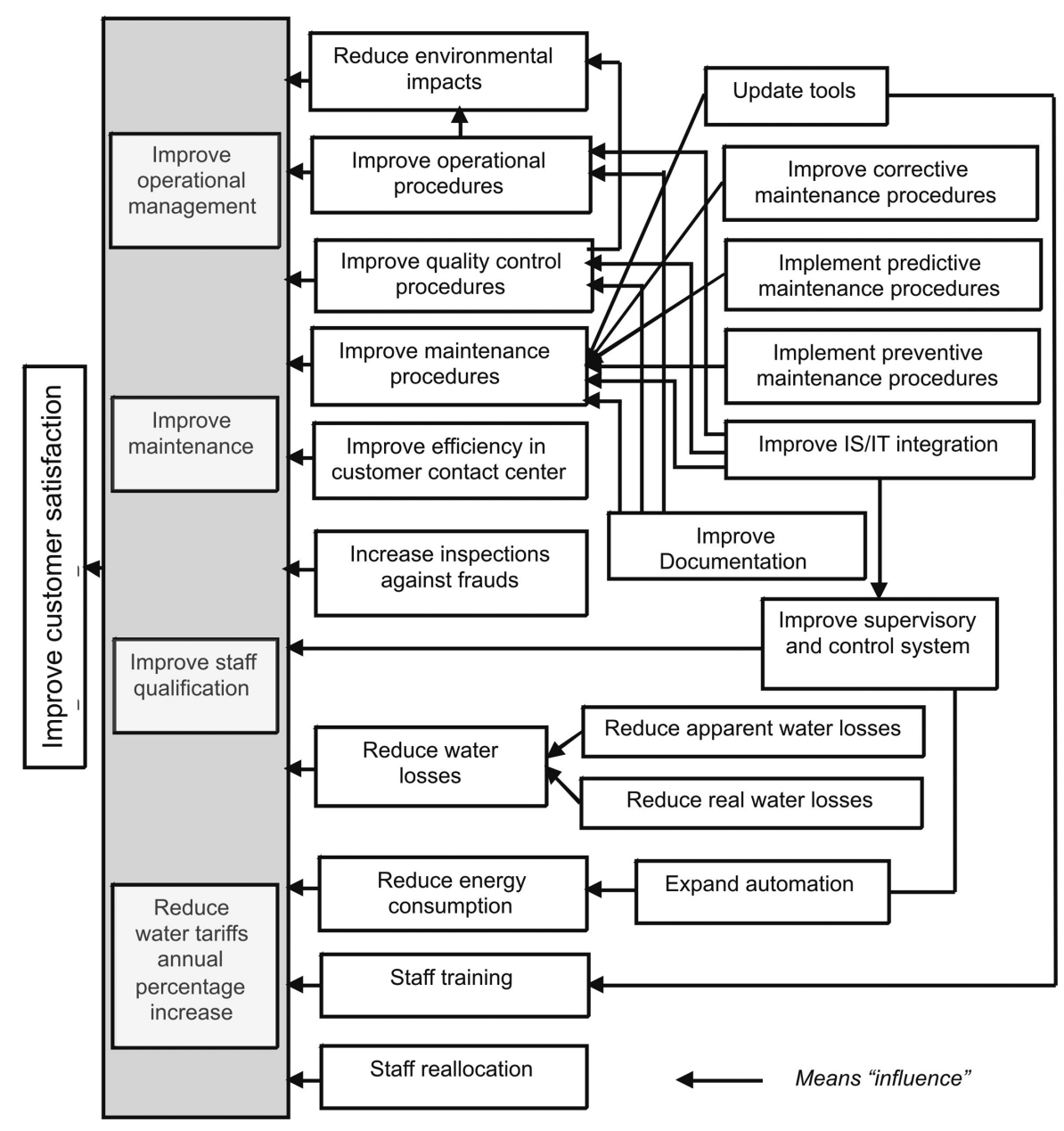

Figure 1 - Network of means-ends objectives for the Water Utility.

- Environmental: A 20\% upgrade of the current sanitary collection network; Replace $30 \%$ of old pipelines with new ones; Change the coagulant used in treating sewage; Conduct educational campaign; Train chemical and operational staff; Send the sludge to a useful destination.

- Infrastructure: Construct new water stations that are totally automatized; Expand the distribution network by $30 \%$; Implement standards for accepting bids.

- Operational: Automatize water treatment plant and all pump stations; Train operators; Reduce the number of operator staff.

- Maintenance: Train maintenance staff; Use historical data to optimize the preventative maintenance time table; Review available stock and tools; Buy two new vehicles; Only 
emergency procedures in pipelines will be done during the day, others should be done during the night.

- Customer Relationship: Train customer service staff to reduce the time they spend with clients; Create more Internet and ATM services; Increase the numbers of customer service staff in the Call Centers.

- Information Technology: Collect all data in a database; Improve the telecommunication systems; Integrate with corporate IS.

\section{IS/IT STRATEGIC PLANNING}

Alignment between business and IS/IT means integrating IS/IT considerations into the corporate planning process, thus linking IS/IT solutions to business goals and determining the information requisites needed to meet the company's short- and long-term goals. For Schwarz \& Hirschheim (2003), the strategic success of IS/IT is very much related to the way that IS/IT conducts itself, such that it is seen positively both by CIOs and other executives.

This application investigates alternative forms of alignment between business and IS/IT using the VFT approach to create such alternatives. The case study was conducted in a Public Energy Company (Hydro-Electric Power) in Brazil, which has a typical IS/IT area. The IS/IT function has a well defined role in the Company and there is a formal organizational unit to manage the IS/IT. Two CIOs were interviewed using a structured approach with open questions based on guideline questions proposed by the VFT approach.

From the standpoint of the CIOs interviewed, knowledge of the company's strategic plan is not great and IS/IT does not participate in helping to shape the business plan. On the other hand, IS/IT does not have a corporate vision on achieving these plans which creates some conflicts. Consequently, the vision of partnership, credibility, and trust from the user are partial.

Although the CIOs interviewed believe that IS/IT has won recognition and sponsorship from the CEO, there is only administrative integration between IS/IT and business, and there are some problems regarding communication and relationships with the user. The CIOs interviewed consider that IS/IT takes a reactive stance, and responds to demands. IS/IT is wrapped up in itself and does not go to the user. In summary, as a consequence that was explained, no user sees the IS/IT Department as a solver of organizational problems and, despite sponsorship from the CEO, the strategic potential of IS/IT is not recognized either by the CEO or by users. Hence, the IS/IT strategic potential is not completely used by the Company and the IS/IT Function is used only to deal with operational problems.

Having understood the decision context and the CIOs interviewed desires for IS/IT, the following wish list of objectives was obtained:

- to be recognized on account of IS/IT improving the business;

- to be recognized as a strategic partner; 
- to be sponsored;

- to receive resources for all IS/IT initiatives.

Some specific problems mentioned by the CIOs as impediments to fulfilling the items on the wish list were lack of an IS/IT committee to discuss technical and business decisions, qualitative and quantitative features of professionals, cultural problems (a cultural gap between new and old professionals), and lack of a service model (with prioritization and performance measures).

The CIOs views were seen to be similar and complementary to each other. There is no perception of conflict between them. From the list of objectives, the hierarchy of fundamental objectives in Table 2 was constructed. Some proposed objectives in an earlier draft of the hierarchy were recognized as means objectives and removed from the hierarchy of fundamental objectives.

Table 2 - IS/IT hierarchy of fundamental objectives.

\begin{tabular}{|l|}
\hline Strategic objective: IS/IT to support Business Strategies \\
\hline 1. Promote competitive advantage for the business \\
1.1. Improve business value \\
1.2. Understand the business's needs \\
\hline 2. Reduce costs \\
2.1. Promote operational efficiency \\
2.2. Promote effectiveness \\
\hline 3. Have a good visibility/credibility \\
3.1. Improve users' satisfaction \\
3.2. Be sponsored by the CEO \\
\hline
\end{tabular}

A specific attribute was defined for each lower-level fundamental objective. This resulted in six evaluation measures: five natural attributes and one constructed attribute. The natural ones were amount (reais) of cost reductions, reductions in the time that processes take, percent of IS/IT solution for business problem proposal by IS/IT area, amount (reais) of increase in profits, percent of revenue invested in IS/IT. The constructed attribute was a perception/opinion measure, applied to the company's professionals.

The means objectives from the CIOs' standpoint are important because of their implication for some other objectives. Following the VFT approach, the network of means-ends objectives in Figure 2 was constructed.

The alternatives for the alignment problem between business and IS/IT in this study were identified from the fundamental and means objectives derived from the interviews with the CIOs, and are also based on the specific problems that were described by the CIOs as impediments to reaching their objectives.

In the process to create alternatives, some important aspects mentioned in the literature from previous research were considered, such as planning IS/IT from a strategic view, being familiar 


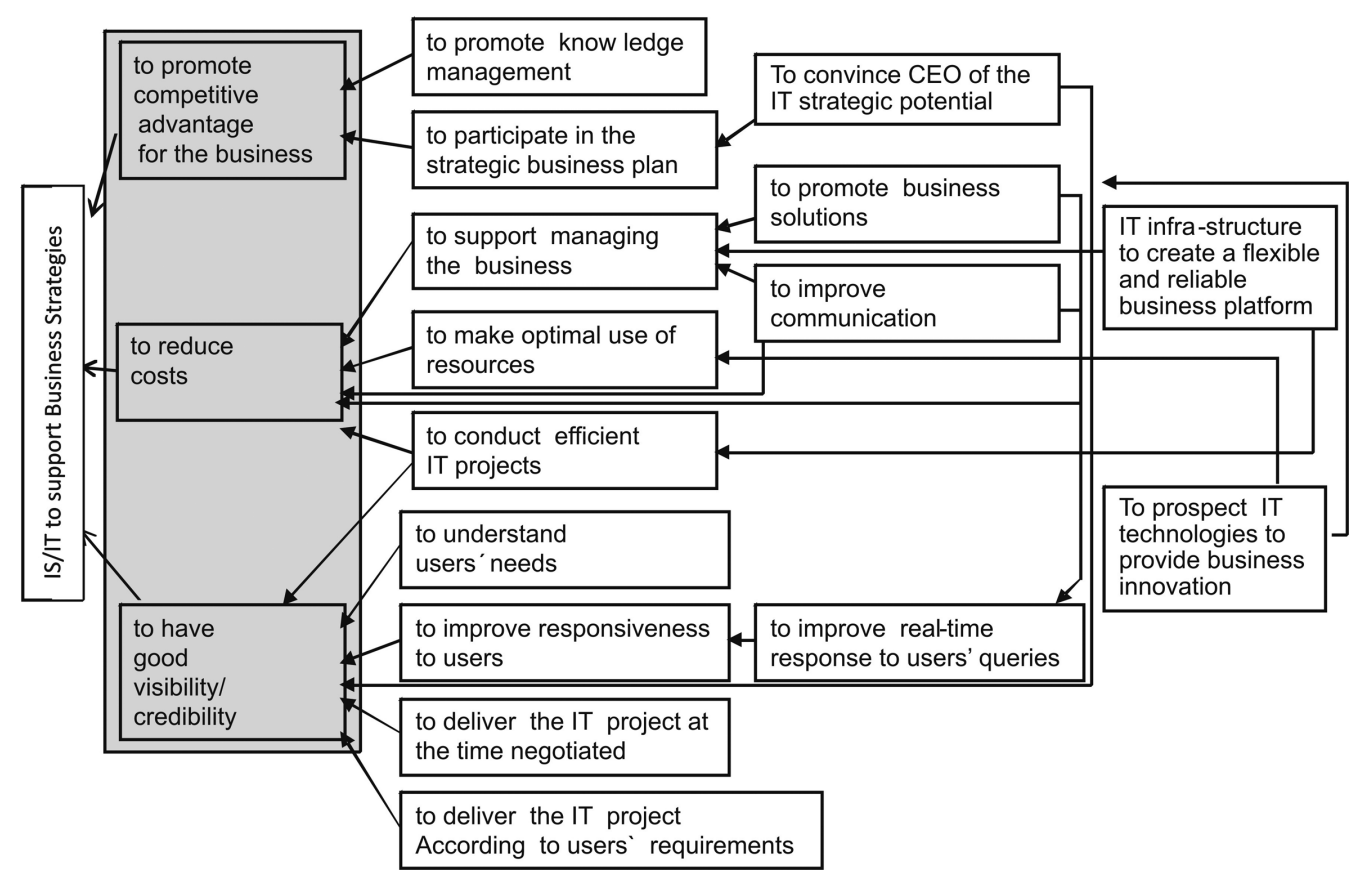

Figure 2 - IS/IT Network of Means-Ends Objectives.

with business information requirements, and giving value to the partnerships with users. The ideas that were generated include the following:

- IS/IT Plan is drawn up from an organizational strategic view.

- IS/IT provides a business process that is adaptable, effective and cost efficient.

- To identify organizational information requirements.

- To design business processes.

- To provide systems that will enable the business unit to meet clients' needs efficiently, reliably and timely.

- To provide systems that respond to business challenges and opportunities.

- To improve the management of the relationship with the user.

- To set up an IS/IT committee.

- To undertake an IS/IT project that displays high apparent impact for the business at low cost in the minimal possible time.

- To audit systems in the whole life cycle.

- To establish and negotiate service levels with the user.

- To implement a support service for the user.

- To implement a performance available system for IS/IT. 
- To prospect /implement an IS/IT solution for sharing knowledge.

- To construct and maintain a collaborative and harmonious relationship with user and business manager.

Some of the ideas generated emphasized the importance of the CIOs being close to the company's business areas. The use of the VFT approach allowed the CIOs to notice the importance of the aspects previously mentioned when alternatives were identified, including the way in which the IT area must conduct itself to foster what is seen positively by the other areas of the organization.

\section{DISPOSING OF PLASTER WASTE FROM BUILDING SITES}

Civil construction is an industry that uses large volumes of materials and is responsible for a large amount of the construction waste generated in the world. Plaster is among the materials that are used and produce waste. The problems caused by plaster waste are mainly related to environmental aspects, since there is no adequate means to dispose of them. One of the ideas that some construction companies were considering was related to substituting another material that does not have this problem for plaster. This substitution could bring another problem with huge impacts, namely slowing the economic development of a specific region in Brazil. According to Sindusgesso (2011), 95\% of the production of gypsum in Brazil is from the region of Araripe, in Pernambuco. The VFT methodology was applied to structure the problem of plaster waste, with the intent to maintain its use in building sites (Alencar et al., 2011).

In Brazil, there is a legal resolution - the resolution of the national council for the environment (CONAMA, 2002) - that requires some actions that must be taken to reduce the environmental impact of wastes from civil construction sites. According to this resolution, plaster waste belongs to class $\mathrm{C}$, which concerns wastes for which economically viable technologies or applications for its reuse or reapplication have not yet been developed.

Thus, building site companies and companies of plasterers are both trying to find solutions for the problem of how to dispose correctly the waste generated when plaster is used. The VFT methodology was applied to structure the fundamental values of those involved and, from this structure, to create a set of possible alternatives for solution (Alencar et al., 2011). Some meetings and discussions were held with a representative committee to try to identify the objectives of the problem and to find solutions for it. Different ways of asking questions were used with the aim of making the committee think about the problem objectives not only in the context of their own business, but also in other contexts. As a result, information to construct the hierarchy of the fundamental objectives in Table 3 and a means-ends objectives network in Figure 3 were obtained. The means-ends objectives network shows the relations of the fundamental objectives to all of the other objectives identified in the discussions.

The definition of the attributes to measure the higher-level fundamental objectives in Table 3 were made based on the means-end objective network. They are the following: 
Table 3 - Strategic objective and hierarchy of the fundamental objectives for plaster work.

\begin{tabular}{|l|}
\hline $\begin{array}{c}\text { Maximize the use of plaster on building sites contributing } \\
\text { to regional economic development (strategic objective) }\end{array}$ \\
\hline 1. Maximize protecting the environmental and health aspects \\
1.1. Mimimize the contamination of water \\
1.2. Minimize public disturbance (including health problems) \\
1.3. Comply with the current regulations \\
1.4. Obtain environmental certification \\
\hline 2. Maximize the use of plaster \\
2.1. Minimize the cost of investment in technology \\
2.2. Maximize the engagement of the companies \\
2.3. Minimize the cost of plaster \\
\hline 3. Improve the company image \\
3.1. As seen by customers \\
3.2. As seen by other companies \\
4. Minimize the non-purposeful exploration of gypsum by \\
4.1. Plastering company \\
4.2. Construction company \\
\hline 5. Maximize quality of service \\
5.1. Maximize productivity \\
5.1.1. First use of plaster \\
5.1.2. Re-use of plaster \\
5.2. Improve construction techniques \\
5.3. Give more and better training to the staff \\
5.4. Bring about Culture change in support of quality \\
5.5. Maximize the quality of service to customers \\
\hline
\end{tabular}

1. Environmental and Health Aspects

a. contamination of the water

b. dispersion of $\mathrm{H}_{2} \mathrm{~S}$

2. Maximize the use of plaster
a. the investment in new technologies in the first year
b. plaster cost
c. fraction of investment in new technologies in the first year

3. Company Image

a. Public satisfaction

4. Non-useful exploitation of Gypsum

a. the time taken to remove plaster waste per $\mathrm{m}^{2}$ applied 


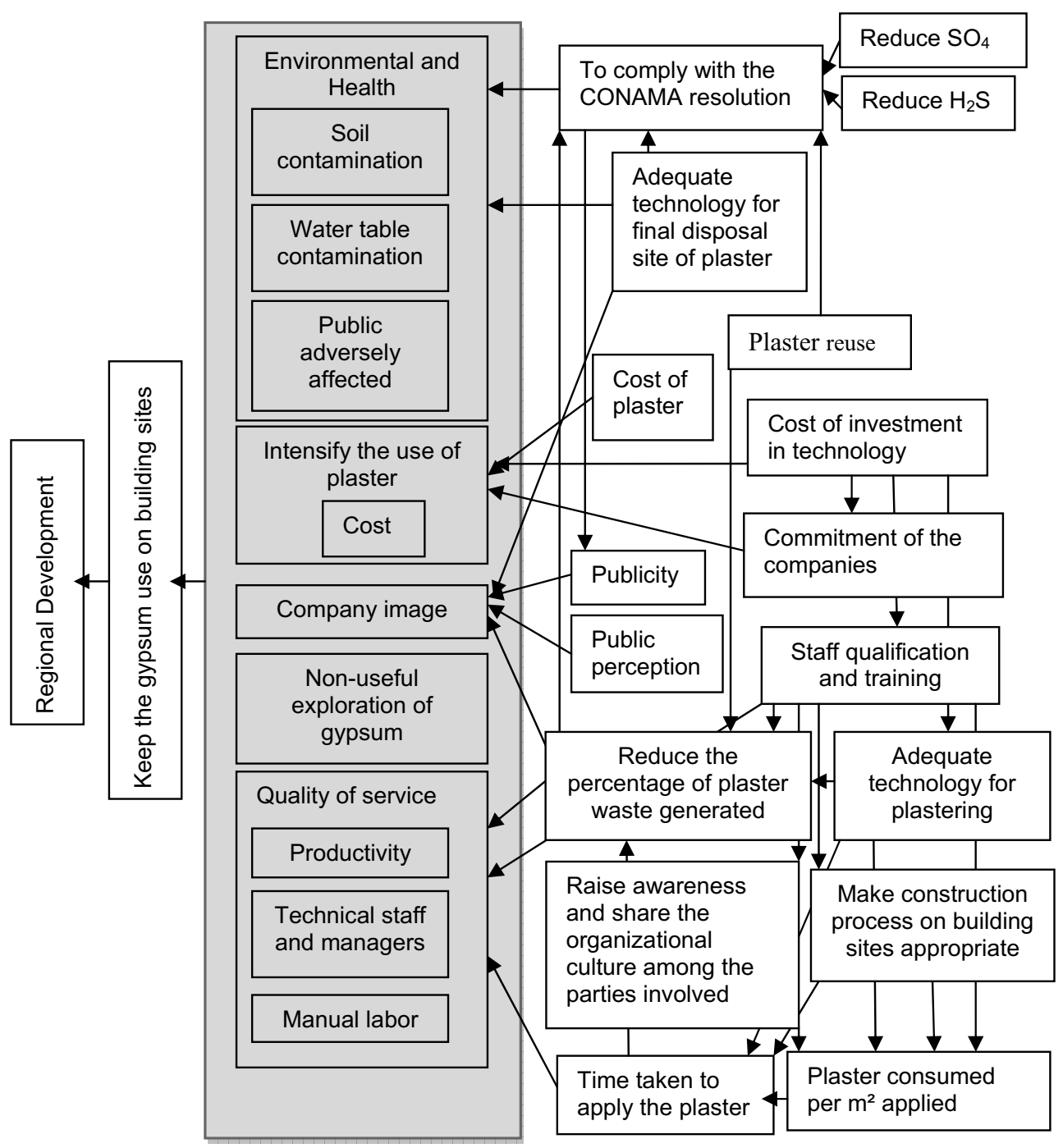

Figure 3 - Means-ends objectives network (source: Alencar et al., 2011).

5. Quality of Service

a. the time taken to remove plaster waste per $\mathrm{m}^{2}$ applied

b. the ratio of the waste reused to the amount of plaster waste generated $\left(\mathrm{kg} / \mathrm{m}^{2}\right)$

i. the amount of plaster waste generated $\left(\mathrm{kg} / \mathrm{m}^{2}\right)$

ii. the percent reuse of plaster waste

c. Maximize the time the plaster takes to set 
Table 3 and Figure 3 supported the generation of alternatives or parts of alternatives for possible solutions for the problem. Details of this process are found in Alencar et al. (2011). Examples of ideas generated in the creative process include the following:

- Develop campaigns with the unions to foster commitment in construction and applying companies.

- Act together with the government with the aim of introducing and advertising fiscal incentives for training and skills-giving courses for manual laborers.

- Reuse the plaster waste by constructing new material for use at the building site (decorative pieces, reference point of width, etc.).

- Develop and use new technology for applying plaster.

- Develop campaigns or actions for training, informing, and educating manual laborers on the negative impacts of plaster waste.

- Invest in educational planning.

- Invest in material/tools for better use.

- Government actively publicizes those companies that are making investments with the aim of involving more companies and improving the companies' image.

- Use new technology in the reuse of plaster waste.

- Study the addition of reagent to increase the time the plaster takes to set within the limits of the cost of plaster.

- Conduct a study on what would be the best or most adequate receptacle in which to store plaster waste.

- Decide on frequencies of transportation - collect/transfer the amount to be transported at periodic intervals of time.

- Decide how to transfer small amounts of plasterboard by making use of a waste transfer station, where it is bulked and then delivered to a recycler.

\section{CREATING ALTERNATIVES}

The creation of alternatives for a given problem is not an easy process. People are not used to developing alternatives, and in most cases the alternatives that come to mind are those that are already know by those involved in the process.

This was what happened in first thoughts on the plaster disposal application. The first ideas that were generated as possible actions were those that someone on the committee had used 
before in some situation or some obvious thought that did not exactly represent an alternative. Thereafter, it was explained the alternatives should be developed through the values that were specified when the problem was structured, thus trying to remove the anchor of the obvious alternatives that come to mind. The generation of alternatives was supported by the prioritization of the objectives that was previously done. In this way, the process of generating some new ideas for developing alternatives were developed and it was noted that some alternatives served as basis for generating new ones.

The procedure used in all applications in Brazil for creating alternatives began with analyzing each objective separately and then each pair of objectives. After generating several suggestions for alternatives, discussions were held with the people involved to try to eliminate redundancies and to combine some potential alternatives into additional new alternatives. As a result, a set of ideas for the alternatives was obtained.

In the water management application, it was noted that if DMs worked with two or more objectives, they did not generate new ideas for alternatives. Instead, they realized the relationship in implementing one alternative to better achieve one objective should have a beneficial direct influence on another objective. For instance, the alternative of "automatize pump stations" created to better achieve the operational management, has a direct influence on the need to expand and modernize infrastructure, because the quantity and pressure of water pumped will affect the required diameter of the pipes. Also this alternative will affect the maintenance system, since automatized systems will improve maintenance control procedures.

In the IT application, the CIOs started to think about important aspects such as coordinating with the user, communication, and relationship management. Many ideas generated suggest the importance of frequent communication between the IS/IT area and users for bringing about an alignment between IS/IT and business.

Deep and persistent thought is useful in creating alternatives. In developing alternatives for the applications, there was a necessity to think about how to achieve the objectives in the fundamental objectives hierarchy of each problem situation. In doing this, several alternatives were created that often had redundancies with each other. Then, some workshops were held with the aim of presenting and discussing the list of suggestions for the alternatives that were generated. In these workshops, several new alternatives that were generated essentially combined existing alternatives.

Since any alternative influences at least one means objective, it will influence at least one fundamental objective. Hence, after refining the alternatives, their implications were traced through the means-ends objectives network to see their influences on the fundamental objectives.

The evaluation of the alternatives is the last stage of the process to select an alternative, or alternatives, to implement. The evaluation can result from a formal decision analysis using the utility function or value function that was developed to better understand the relative importance of the various fundamental objectives. In many cases, the clearer understanding of the implications of the various alternatives afforded with value-focused thinking allows one to understand how each 
alternative measures up in terms of the fundamental objectives. Hence, an informed decision can be made in many cases without the additional insight provided by a formal analysis.

\section{CONCLUSION}

This paper presented three cases of the application of the VFT approach in Brazil. It indicates that VFT can be very useful for structuring and solving problems with multiple objectives and multiple parties. After the objectives of each party have been developed, they can usefully guide the generation of more efficient alternatives for the problem solution.

One of the main contributions of the application in all the studies developed was to establish the means-ends network of objectives that provided a complete understanding of each problem to all interested parties. The benefits obtained from this structure are diverse and specific to each case studied.

The cases presented show the VFT approach to be a useful decision tool to create alternatives for the decision problem. It has shown that VFT is practical and feasible for supporting organizational decision problems since it is natural for decision-makers to think in terms of requirements, constraints, and objectives to meet the problems. VFT is intended to help them do what is natural in a more thorough and systematic way and to provide them with a logical organization of all of their thoughts.

\section{REFERENCES}

[1] Alencar LH, Mota CM \& Alencar MH. 2011. The problem of disposing of plaster waste from building sites: Problem structuring based on value focus thinking methodology. Waste Management, 31(12): 2512-2521.

[2] CONAMA. 2002. Resolution 307: Established directives, guidelines and procedures for the management of construction.

[3] HASSAN OAB. 2004. Application of value-focused thinking on the environmental selection of wall structures. Journal of Environmental Management, 70: 181-187.

[4] Jurk DM, Chambal SP \& Thal AE. 2004. Using value-focused thinking to select innovative force protection ideas. Military Operations Research, 9(3): 31-43.

[5] Kajanus M, Kangasb J \& Kurttilac M. 2004. The use of value focused thinking and the A'WOT hybrid method in tourism management. Tourism Management, 25: 499-506.

[6] Keeney GL \& Winterfeldt DV. 2010. Identifying and Structuring the Objectives of Terrorists. Risk Analysis, 30(12): 1803-1816.

[7] Keeney RL \& McDaniels TL. 2001. A Framework to Guide Thinking and Analysis Regarding Climate Change Policies. Risk Analysis, 21(6): 989-1000.

[8] KeEney RL. 2001. Modeling Values for Telecommunications Management. IEEE Transactions on Engineering Management, 48(3): 370-379.

[9] Keeney RL. 1992. Value Focused Thinking. Harvard University Press, London. 
[10] Keeney RL. 2007. Developing Objectives and Attributes, in Advances in Decision Analysis [edited by W. Edwards, R.F. Miles and Detlof von Winterfeldt], Cambridge University Press, 104-128.

[11] MERRICK JRW \& GARCIA MW. 2004. Using value-focused thinking to improve watersheds. Journal of the American Planning Association, 70(3): 313-327.

[12] Merrick JRW, Grabowski M, Ayyalasomayajula P \& Harrald JR. 2005. Understanding Organizational Safety Using Value-Focused Thinking. Risk Analysis, 25(4): 1029-1041.

[13] PARNell GS \& Hill RR. 2008. Value-focused thinking and the challenges of the long war. Military Operations Research, 13: 2-5.

[14] Peharda I \& HunjaK T. 2008. Selecting an Automatic Rifle using the Value-focused Thinking Approach. Military Operations Research, 13(3): 19-26.

[15] SChwarz A \& HirSChein R. 2003. An extended platform logic perspective of IT governance: managing perceptions and activities of TI. Journal of Strategic Informations Systems, 12: 129-166.

[16] Selart M \& TVEDT JS. 2011. Understanding the role of value-focused thinking in idea management. Creativity and Innovation Management, 20(3): 196-206.

[17] Sheng H, NAh FF \& SiaU K. 2005. Strategic implications of mobile technology - A case study using Value-Focused Thinking. Journal of Strategic Information Systems, 14: 269-290.

[18] Sheng H, NAH FF \& SiAU K. 2010. Understanding the values of mobile technology in education: a value-focused thinking approach. Data Base for Advances in Information Systems, 41: 25-44.

[19] Sindusgesso - Sindicato da Indústria do Gesso do Estado de Pernambuco (Union for the Plaster Industries of Pernambuco). 2011. Pólo Gesseiro - Gypsum pole. Available from: <http://www.sindusgesso.org.br/polo_gesseiro.asp > (accessed June 2011). 